SHORT REPORT

\title{
Geographic mobility following cancer treatment in Yorkshire, UK
}

\author{
R G Feltbower, A W Glaser, R C Parslow, S E Kinsey
}

Arch Dis Child 2004;89:380-381. doi: 10.1136/adc.2002.022061

Long term cure and maximising reintegration into society are major goals of childhood cancer treatment. Whether reintegration had occurred was assessed using geographic mobility as an objective proxy. Age, sex, and socioeconomic status were identified as being independently associated with mobility whereas diagnosis and relapse were not.

$\mathrm{S}$ urvival from childhood malignancy exceeds $70 \%$, with 1 in 1000 young adults estimated to be survivors. ${ }^{1}$ Long term cure and maximising a patient's reintegration into society are two major goals of any childhood cancer unit, but information relating to long term quality of survival, and associated morbidity burden, is sparse. Assessment of reintegration is made difficult by multiple factors, including the wide range of activity seen within the general population. In particular, there is no information relating to mobility/ migration for young people and their families diagnosed with cancer. Proxy indicators of activity and functioning within society are required, as no gold standard assessment tool is available. We propose using geographic mobility as a proxy measure. While recognising that this may not reflect social reintegration per se, it is a simple measure and easily replicable in other studies.

We set out to assess firstly whether reintegration had occurred using geographic mobility as an objective proxy, secondly to investigate the a priori hypothesis that increased morbidity from cancer reduces mobility, and thirdly to examine factors which might influence mobility.

\section{METHODS}

Details of children diagnosed with a malignancy aged 0-14 years and remaining alive five years post-diagnosis were extracted from the Yorkshire Specialist Register of Cancer in Children and Young People. ${ }^{2}$ This population based register covers a childhood population of around 700000 in the north of England. For each surviving child, residential addresses and postcodes are updated biennially from hospital records and GP notifications, and then validated using QuickAddress. Mobility was defined by any address different to that at diagnosis and analysed using logistic regression (moved: yes/ no), investigating simultaneously the effects of age $(>18 \mathrm{v}$ $<18$ years), sex, socioeconomic status (based on the Townsend deprivation score divided into quintiles), treatment with a bone marrow transplant (BMT, yes/no), and cranial irradiation (yes/no).

\section{RESULTS}

A total of 931 long term survivors of cancer were identified (table 1). No significant difference in mobility (that is, the number of moves) was observed across the four main diagnostic groups (Kruskal-Wallis, $\mathrm{p}=0.14$ ). The majority either had not moved $(50 \%)$ or moved once $(35 \%)$. Of those patients who changed address at least once, the distance they moved each time did not differ significantly by diagnostic group (Kruskal-Wallis, $\mathrm{p}=0.23$ ). Those currently aged 18 or over were more likely to move than those under 18 (58\% $\mathrm{v}$ $41 \%$ ). For all cancers, girls were $18 \%$ more likely to move than boys, and this effect increased to $74 \%$ for acute lymphoblastic leukaemia $(p=0.052)$. Children living in less affluent areas were more likely to move, particularly those with leukaemia (table 2), although a test for trend for each odds ratio across quintiles was not significant $(p=0.34)$. Cranial irradiation had no effect on mobility of survivors of brain tumours (47\% who had irradiation had moved versus $48 \%$ who had no irradiation). Relapse did not alter mobility significantly $(43 \%$ of those who had relapsed had moved versus $51 \%$ who had not relapsed, $\mathrm{p}=0.31$ ). Following BMT, children with leukaemia/lymphoma were $11 \%$ less likely to have moved $(40 \%$ with a BMT had moved versus $51 \%$ without).

\section{DISCUSSION}

We report the first population based series examining geographic mobility of childhood cancer survivors as a proxy for social reintegration and morbidity burden associated with survival. The proportion of children who moved was remarkably similar across diagnostic groups. No significant difference in the proportion of movers was found for patients who had relapsed from any form of cancer or for CNS tumour survivors who received cranial irradiation compared with those who did not. These groups might be assumed to have a higher morbidity burden following increased intensity of therapy, ${ }^{3}$ as was found for lymphoma/leukaemia survivors who received dose intensive therapy associated with BMT.

Age, sex, and socioeconomic status were identified as being independently associated with mobility. Shelton and Grundy, ${ }^{4}$ in a study investigating the proximity of children to their parents, found that educational level was the most important factor influencing mobility and which is likely to explain the association we observed with socioeconomic status. The Social Change and Economic Life Initiative study ${ }^{5}$ examined mobility on a sample of 350 men from Rochdale in the northwest of England and found that migration was linked with age, marital status, employment, and duration of stay.

A US study ${ }^{6}$ of 10000 households revealed that $74 \%$ of young people aged 6-17 years had moved at least once and $39 \%$ had moved three or more times in their lifetime. No differences in mobility were observed by mother's education, ethnic group, or sex; however, mobility was more common for older children and those in families above the poverty index (that is, more deprived). The sample was representative of the population and had a $91 \%$ response rate. No normative data were available in the UK. Data from the 2001 national census (www.nationalstatistics.gov.uk/census2001/default. asp) when released over the next few years may provide 
Table 1 Frequency of cancer in children five years post-treatment in Yorkshire, UK

\begin{tabular}{|c|c|c|c|c|c|c|c|c|}
\hline & \multicolumn{2}{|c|}{ Leukaemias } & \multicolumn{2}{|c|}{ Lymphomas } & \multicolumn{2}{|l|}{ CNS } & \multicolumn{2}{|c|}{ Solid tumours } \\
\hline & $\mathbf{n}$ & $\%$ moved & $\mathbf{n}$ & $\%$ moved & n & $\%$ moved & $\mathbf{n}$ & $\%$ moved \\
\hline \multicolumn{9}{|l|}{ Age group } \\
\hline $0-4$ & 154 & $46.8 \%$ & 34 & $73.5 \%$ & 45 & $51.1 \%$ & 193 & $50.3 \%$ \\
\hline $5-9$ & 71 & $47.9 \%$ & 49 & $42.9 \%$ & 53 & $41.5 \%$ & 62 & $58.1 \%$ \\
\hline $10-14$ & 42 & $57.1 \%$ & 71 & $56.3 \%$ & 68 & $48.5 \%$ & 89 & $50.6 \%$ \\
\hline \multicolumn{9}{|l|}{ Sex } \\
\hline Male & 135 & $45.2 \%$ & 111 & $50.5 \%$ & 93 & $48.4 \%$ & 166 & $51.2 \%$ \\
\hline Female & 132 & $52.3 \%$ & 43 & $69.8 \%$ & 73 & $45.2 \%$ & 178 & $52.3 \%$ \\
\hline Total & 267 & $48.7 \%$ & 154 & $55.8 \%$ & 166 & $47.0 \%$ & 344 & $51.7 \%$ \\
\hline
\end{tabular}

Table 2 Likelihood of moving according to age, sex, and socioeconomic status (Townsend score) for children with any type of cancer and leukaemia in Yorkshire, UK

\begin{tabular}{|c|c|c|c|c|}
\hline & \multicolumn{2}{|l|}{ All cancers } & \multicolumn{2}{|l|}{ Leukaemia } \\
\hline & Odds ratio & $95 \% \mathrm{Cl}$ & Odds ratio & $95 \% \mathrm{Cl}$ \\
\hline \multicolumn{5}{|l|}{ Age } \\
\hline$>18$ years & 1.00 & & 1.00 & \\
\hline$<18$ years & 0.49 & 0.37 to 0.64 & 0.40 & 0.24 to 0.68 \\
\hline \multicolumn{5}{|l|}{ Sex } \\
\hline Male & 1.00 & & 1.00 & \\
\hline Female & 1.18 & 0.90 to 1.53 & 1.42 & 0.86 to 2.36 \\
\hline \multicolumn{5}{|c|}{ Socioeconomic status (Townsend score ${ }^{7}$ ) } \\
\hline Most affluent & 1.00 & & 1.00 & \\
\hline$\downarrow$ & 1.28 & 0.84 to 1.94 & 3.26 & 1.47 to 7.20 \\
\hline$\downarrow$ & 1.31 & 0.87 to 1.99 & 1.88 & 0.84 to 4.21 \\
\hline$\downarrow$ & 1.45 & 0.96 to 2.20 & 2.15 & 0.97 to 4.78 \\
\hline Least affluent & 1.37 & 0.90 to 2.07 & 1.85 & 0.82 to 4.17 \\
\hline
\end{tabular}

more detailed information on population mobility and migration statistics. The effects of educational level, employment, and family circumstance (for example, marital status, independent living, number of parents present in the family) on survival from childhood cancer need to be specifically explored. The ongoing British Childhood Cancer Survivors Study may provide information pertaining to these variables.

\section{ACKNOWLEDGEMENTS}

We are grateful for the help and co-operation of all local medical records' staff. We also thank Dr Tricia McKinney for comments on the manuscript.

\section{Authors' affiliations}

R Feltbower, R Parslow, Paediatric Epidemiology Group, Unit of Epidemiology \& Health Services Research, University of Leeds, Leeds LS2 9LN, UK

A Glaser, S Kinsey, Paediatric Oncology \& Haematology, Children's Day Hospital, St James's University Hospital, Leeds LS9 7TF, UK
Correspondence to: Mr R Feltbower, Paediatric Epidemiology Group, Unit of Epidemiology \& Health Services Research, University of Leeds, Leeds LS2 9LN, UK; r.g.feltbower@leeds.ac.uk

Accepted 18 June 2003

\section{REFERENCES}

1 Coleman MP, Babb P, Damiecki P, et al. Cancer survival trends in England and Wales, 1971-1995: deprivation and NHS region. London: The Stationery Office, 1999:68.

2 McKinney PA, Feltbower RG, Parslow RC, et al. Survival from childhood cancer in Yorkshire UK: effect of ethnicity and deprivation. Eur $J$ Cancer 1999;35:1816-23.

3 Wallace WHB, Blacklay A, Eiser C, et al. Developing strategies for long term follow-up of survivors of childhood cancer. BMJ 2001;323:271-4.

4 Shelton NJ, Grundy E. Proximity of adult children to their parents in Great Britain. Int J Popul Geogr 2000;6:181-95.

5 Social Change and Economic Life Initiative, 1996. http://tramss.dataarchive.ac.uk/documentation/migration/migpag 1.htm.

6 Simpson GA, Fowler MG. Geographic mobility and children's emotional/ behavioral adjustment and school functioning. Pediatrics 1994;93:303-9.

7 Phillimore $P$, Beattie A, Townsend P. Widening inequality of health in northern England, 1981-91. BMJ 1994;308:1125-8. 